\title{
Stromal Dynamic Reciprocity in Cancer: Intricacies of Fibroblastic-ECM Interactions
}

${ }^{1,2}$ Jennifer Alexander and ${ }^{1}$ Edna Cukierman*

${ }^{1}$ Fox Chase Cancer Center, Cancer Biology, Temple Health, 333 Cottman Ave, Philadelphia, PA 19111, USA

${ }^{2}$ Drexel University College of Medicine, Department of Molecular Biology and Biochemistry, $245 \mathrm{~N} 15^{\text {th }}$

St, Philadelphia, PA 19102

*Corresponding author - edna.cukierman@fccc.edu

\section{Abstract:}

Stromal dynamic reciprocity (SDR) consists of the biophysical and biochemical interplay between connective tissue elements that regulate and maintain organ homeostasis. In epithelial cancers, chronic alterations of SDR result in the once tumor-restrictive stroma evolving into a "new" tumor-permissive environment. This altered stroma, known as desmoplasia, is initiated and maintained by cancer associated fibroblasts (CAFs) that remodel the extracellular matrix (ECM). Desmoplasia fuels a vicious cycle of stromal dissemination enriching both CAFs and desmoplastic ECM. Targeting specific drivers of desmoplasia, such as CAFs, either enhances or halts tumor growth and progression. These conflicting effects suggest that stromal interactions are not fully understood. This review highlights known fibroblastic-ECM interactions in an effort to encourage therapies that will restore cancer-restrictive stromal cues.

\section{Introduction}

Centuries of research corroborate the mesenchymal-stroma accompanying epithelial cancers to be more than an impartial bystander providing mechanical and nutritional support to tumors [1,2]. The stromal compartment is vastly diverse in cellular and extracellular composition across all tissue environments. It is comprised of fat, immune, endothelial and fibroblastic cells as well as a fibroblastic-derived extracellular matrix (ECM). This ECM is rich in fibrous proteins such as type I collagen and fibronectin. It contains proteoglycans, cytokines, chemokines, matricellular proteins such as tenascins, secreted protein acidic and rich in cysteine (SPARC), periostin, and many others which become accessible to cells upon enzymatic and mechanical alterations to the ECM [3-6].

The natural (innate) role of the mesenchymal-stroma is to impart a tightly controlled environment, which in consequence maintains a tumor-repressive homeostatic equilibrium regulated by local fibroblastic cells. The innate stroma accomplishes this by reinstating balance within the tissue in response to growth or temporary assaults $[1,5,7-9]$. However, instances such as chronic inflammation and cancer impede restoration of an innate mesenchymal homeostatic state $[3,10]$. When this occurs, stromal components collectively evolve to establish a "new" equilibrium that consequently preserves a pathological condition [11-13]. This type of homeostatic stromal shift is evident in most carcinomas in which the stroma compartment becomes heavily enriched in a well-maintained fibrosis-like reaction known as desmoplasia (Figure 1). Desmoplasia is the pathological term that is commonly used to describe the fibrous mesenchymal reaction that usually creates a stiff stromal environment in numerous epithelial cancers. This desmoplastic stroma is enriched in activated fibroblastic cells (myofibroblast) that are responsible for distinct architectural changes in the ECM, such as increased type I collagen deposition, selective inclusion of fibronectin splice variants (e.g., ED-A), hyaluronic acid, tenascin-C and 
more [10]. Hence, desmoplastic ECMs are typically stiff and organized in parallel-aligned fiber patterns (i.e., anisotropy) $[14,15]$. Eventually, these cellular and ECM alterations generate an environment that is no longer tumor-repressive.

It is well established that malignant (e.g., teratoma) cells are capable of tumor formation within permissive environments. However, when these cells are introduced into a tumor-restrictive microenvironment, the malignant characteristics are soon reverted to that of normal cells. These findings suggest that the plasticity of malignant cells tolerates "reversal to normalcy," allowing cells to differentiate in a non-pathological manner and incorporate into functional tissues/organs [16]. These types of studies demonstrated that unaltered natural mesenchyme can be restrictive of tumor growth while ECM modifications, such as fiber degradation via matrix metalloproteinases (MMPs), can alter the stroma to become tumor permissive [17].

Likewise, stromal influences became evident during experiments that resulted in tumor formation in the absence of malignant epithelial cell contributions. During these experiments, mammary fat pads were pre-cleared from epithelial components and subjected to ionizing radiation. Subsequent to radiation, treated fat-pads were re-populated with un-irradiated non-tumorigenic epithelial cells which consequently developed tumors. Results revealed that radiation-activated stroma promotes tumor formation in otherwise non-tumorigenic cells [18]. Similarly, chronic treatment of stroma with chemical irritants also established tumor permissive capabilities [19]. These and similar studies suggest that neoplastic development and progression is tolerated and often enabled by permissive microenvironmental settings such as the rather stable desmoplastic reaction [20-24].

In accordance, decades of research determined that alterations to innate stromal tissue organization akin to chronic wound healing favor (i.e., predispose) cancer onset $[3,25,26]$. As such, ECM remodeling in response to environmental insults correlates with loss of homeostatic tissue-specific coordination that is known to be driven by actomyosin cytoskeletal reorganization [14,27-30]. Taken together, these facts suggest interdependence between stromal architecture and function whereby maintenance of tissue homeostasis relies on the dynamic and reciprocal influences imparted amongst stromal elements $[11,16,20,22,31-33]$.

The focus of this review is to discuss the complex array of relationships that transpire between stromal components and to highlight the microenvironmental interplay that prompts desmoplasia [10,34-38]. Throughout the text in this review, the sum of signaling exchanges, as they solely relate to fibroblastic cells-ECM interactions, are referred to as "stromal dynamic reciprocity" or SDR. We postulate that reversion of the tumor-permissive desmoplastic features to the innate tumor-restrictive stage may halt tumor progression. Therefore, a better understanding of SDR could potentially unveil new avenues of therapeutic intervention in cancer.

\section{Desmoplastic SDR}

"Dynamic reciprocity" (DR) was first described in the early 1980's by Dr. Bissell and colleagues to explain the persistent biochemical and biophysical processes that occur between cells and the ECM [39]. In this manner, it was proposed that the ECM affects cellular activity via changes to the cytoskeleton and subsequently drives the expression and secretion of matrix remodeling molecules, such as collagen cross-linkers and MMPs, which re-structures ECM. It is currently understood that this "mechanotransduction" is modulated through transmembrane cell surface receptors (e.g. integrins) which interact 
with both the ECM and the cytoskeleton [40-43]. The engagement of these bi-directional ECM-cell receptors serves as a link that enables the transmission of physical signals (and not solely chemical cues [44]) from the extracellular environment to the nucleus $[43,45]$.

With this understanding and by introducing the term "biotensegrity," based on Dr. Ingber's original tensegrity definition $[46,47]$, researchers described the role of the actomyosin cytoskeleton as a bridge or "conduit" that enables mechanical changes in the ECM to drive cellular behavior (e.g., myofibroblastic cell activation). Concurrently, this same "conduit" facilitates cell-induced tissue remodeling, such as in the case of ECM alignment, due to cytoskeleton dependent cell contraction $[43,48]$. These intracellular and extracellular events allow cells to mechanically and biochemically "sense" the changing environment thereby effectively addressing the dynamic needs of the tissue. This is accomplished by modifications in cell shape, polarity, differentiation, survival, motility, gene expression and more [22,39]. As such, SDR is possibly best conceptualized when contrasting acute vs. chronic wound healing processes $[3,21,25]$ or innate (i.e. non-pathologic) vs. tumor-associated (i.e., desmoplastic) microenvironmental influences $[3,4,25,26,37,49]$ (Figure 2).

In the case of acute wound healing, stromal cells are temporarily "activated" into myofibroblastic cells capable of engaging in tissue restoration functions such as de novo ECM remodeling, production and contraction. This provisional change in cellular activity is prompted by mechanical cues as well as by cytokines and chemokines released from the damaged tissue's ECM and/or by immune cells recruited to the site of injury. Soon after the insult is repaired, the newly acquired healing state (acute SDR) is once again altered as myofibroblastic cells either senesce or are cleared by natural killer cells, thus ending the transitory myofibroblastic cell functions. Hence, clearing of these cells achieves wound resolution and thus shifts the system back to its innate homeostatic equilibrium $[3,21,50]$. However, the constant presence of instigating events or insults, as is common in chronic inflammatory wound healing, prompts stromal myofibroblastic cells to sustain healing signals and consequently prevents wound resolution [51]. Under these chronic conditions, the tissue is continuously remodeled and progressively loses its ability to restore the natural/innate tissue function $[3,52]$. These same sustained SDR processes take place in cancer-associated desmoplasia [3,53].

During desmoplastic onset, innate stromal features, such as an isotropic ECM landscape and the quiescent state of stromal cells, are vigorously modified such that the ability to halt cancer initiation and progression is diminished. These continuous repair mechanisms result in persistent anisotropic type I collagen matrix deposition that is believed to be caused by increased contractile YAP and Rho actomyosin cytoskeletal changes known to control cell contraction [54]. These, in addition to increased ECM density, constitute a desmoplastic trademark reminiscent of tissue scarring $[3,49,51,55,56]$ (Figure 2). Overall, these observations are in accord with a model whereby desmoplasia is indeed an active participant in cancer initiation, progression, metastasis and maintenance of pro-tumoral inflammation and immunosuppression [33,51,57-59].

Taken together, there are two apparent dynamic and reciprocal processes that transpire throughout the vicious and expanding SDR cycle. The first process establishes the stromal (i.e., myofibroblastic) cellimposed effect that is responsible for remodeling the ECM landscape $[60,61]$. The second process involves an ECM-imposed cellular influence. During both SDR processes, biochemical signaling cascades are regulated through cell-ECM receptors which stimulate intracellular changes mediated by cytoskeletal reorganization $[22,43]$. Although literature reports suggest that the alterations incurred 
during desmoplastic progression fuel the tumorigenic features of cancer cells $[58,62,63]$, many others imply that desmoplasia stalls cancer aggressiveness [64-69]. Together, these findings support the notion that desmoplastic SDR encompasses a complex phenomenon, which necessitates inclusive multidisciplinary and improved research efforts to fully comprehend these dynamic processes in the tumor microenvironment.

\section{Desmoplastic SDR: cancer-associated fibroblasts-ECM interactions}

Within the innate stromal environment of soft connective tissues (e.g.., dermis in skin), fibroblastic cells are stem-like, quiescent and sparsely dispersed mesenchymal cells that reside within a self-derived mesh-like fibrillar ECM. These innate fibroblasts (i.e., vimentin expressing and pan-keratin null mesenchymal cells) are responsible for maintaining tissue topography upon an ever-changing mechanical load [70]. In response to cytokines such as TGF- $\beta$ and/or ECM mechanical and biochemical changes, innate/quiescent fibroblastic cells transition into proto-myofibroblastic cells and subsequently evolve into fully activated myofibroblasts. In fact, TGF- $\beta$ is known to induce the increased deposition of type I collagen during desmoplastic onset by driving this fibroblastic cell transition [71]. As cells transition to activation, they undergo morphological changes that are accompanied by fibrotic ECM production and heterogeneous expression of assorted myofibroblastic markers such as alpha-smooth muscle actin ( $\alpha$-SMA), desmin, palladin, podoplanin, fibroblast specific protein-1 FSP1/S100A4, fibroblast activation protein (FAP), platelet-derived growth factor receptor alpha (PDGFR) and more $[52,72-74]$. Hence, the role of myofibroblasts which are often induced by injury is to mend and contract the ECM as well as restore innate tissue characteristics $[3,7,29,52,70,75-77]$.

The signaling cues that promote fibroblastic transition, such as TGF- $\beta$, do so by rearranging the cytoskeleton. This rearrangement in turn affects the nucleus (i.e., nucleoskeleton) in a way that indirectly regulates changes in chromatin structure [43]. This ultimately leads to increased expression of additional growth factors, cytokines and matrix remodeling molecules (e.g., MMP 9, MMP14, etc.) while also influencing ECM assembly [43,48,78-81]. Collectively, this posits that the "cytoskeletal conduit" functions as the principal mechano-driver by which cell-induced ECM remodeling and ECM-regulated cellular behaviors are conveyed $[20,43,48,82]$. A prime example of the influence imparted by this cytoskeletal conduit can be perceived during the nuclear translocation of myocardin-related transcription factor A (MRTF-A). Upon cell stretching, changes in actin polymerization regulate MRTF-A nuclear translocation [83]. In turn, the accumulation of nuclear MRTF-A triggers expression of $\alpha$-SMA, [84] and together with myosin these modified stress fibers induce cell contraction resulting in ECM rearrangement.

To achieve acute wound resolution following repair or other non-pathological circumstances, myofibroblasts are prone to undergo apoptosis and/or clearance via the recruitment of specialized lymphocytes (e.g. NK cells) [3,52]. However, as previously described, when the myofibroblastic cell population is sustained, it constitutively maintains tissue regeneration responses that suppress immune cell influences. In the case of desmoplasia, this contributes to neoplastic development and progression while simultaneously inhibiting inherent immune tumor-resolution $[3,7,51,52,85,86]$.

In regards to epithelial cancers, persistent stromal myofibroblastic cells are typically referred to as cancer-associated fibroblasts (CAFs) or as tumor-associated fibroblasts (TAFs) $[87,88]$. The phenotypic features of CAFs are believed to be sustained through epigenetic modifications influenced by paracrine signaling triggered by chronic inflammatory and ECM-prompted alterations $[89,90]$. This idea was 
established using sequence-based genome wide DNA methylation profiling of innate fibroblasts and CAFs from human breast, prostate, lung and other organs [91-93]. These observations are consistent with the vast body of literature proposing the need for sustained (spanning several days) inflammatory factors, such as TGF- $\beta$ or changes in particular ECM proteins (i.e., inclusion of fibronectin splice variant ED-A and increase in type I collagen fibrillogenesis), in order to effectively achieve myofibroblastic activation [52,94-97]. These details suggest CAF reversion to its innate tumor-suppressive state may require epigenetic regulation.

On the other hand, fibrotic and desmoplastic stromal environments undergo changes in architecture (i.e., force-dependent fiber alignment) and in composition (i.e., increased type I collagen deposition), which further fuel and sustain myofibroblastic activation [97]. As cells become contractile, there is an increased mechanical strain that stretches ECM fibers in a way that ligands become more or less accessible to receptors such as integrins [98]. For example, the major fibronectin receptor, $\alpha_{5} \beta_{1^{-}}$ integrin, engages fibronectin most efficiently when its critical bindings sites (i.e. RGD and PHSRN) are positioned at an optimal distance from each other. This positioning results from mechanical stretching of the globular protein during early fibrillogenesis and strengthens the ligand-receptor interaction forming a "catch bond". However, as stretching further increases, the optimal distance of these fibronectin domains no longer sustains this type of integrin bond, switching instead to a "slip bond" interaction. Under these conditions, $\alpha_{5} \beta_{1}$-integrin is promptly released enabling additional integrins such as $\alpha_{v} \beta_{3}$ to engage $[99,100]$.

Furthermore, fibronectin splice variants such as ED-A are increasingly incorporated in fibrous and desmoplastic ECMs. These ED-A-rich ECMs present a preference for $\alpha_{4} \beta_{1}$-integrin binding, which in turn induces Rho-dependent cellular contraction that results in fibrosis maintenance and expansion [101]. In addition, when matrix stiffness is increased (i.e., in aligned anisotropic collagen fibers), activation of latent TGF- $\beta$ is effortlessly accomplished by even the slightest of cellular contractions [102]. Also, Li, et. al. demonstrated that mesenchymal cells produce (i.e., de novo) ECMs of diverse characteristics when the stiffness of their underlying substrate is altered [103]. The above-mentioned and other ECM mechanical properties are therefore paramount in both imposing and maintaining CAF activation $[14,29,39,60,104-110]$. Hence, interfering with ECM-induced CAF responses may constitute a therapeutic option that could restore innate (i.e., tumor-restrictive) stroma. Nonetheless, in order to attain a comprehensive understanding of desmoplastic SDR, there is a conceptual need to distinguish between mechanisms responsible for ECM remodeling and ECM-induced cellular responses (i.e., activation and/or maintenance of active myofibroblasts) Figures 2 \& 3.

It is widely understood that, in addition to other stromal and tumoral cells, CAFs abundantly express and secrete TGF- $\beta$. TGF- $\beta$ is stored within stromal ECM in its latent form and becomes activated/processed by both biochemical and mechanical cues resulting from alterations in ECM anisotropy [97]. This constitutive secretion, processing and receptor engagement of TGF- $\beta$ is known to trigger cytoskeletal cell-contractile rearrangements that mediate variations in gene expression (i.e., $\alpha$-SMA [111]), while also maintaining constant mechanical tension at the ECM-cell interface (i.e., via receptor engagement) $[43,112-115]$. The mechanical strain imposed by the altered ECM transmitted via cytoskeletal conduits leads to additional modifications in nuclei shape and chromatin organization $[39,45,116]$. Consistent with these observations, mathematical models investigating the links between communal regulation of ECM and nuclear characteristics (e.g., rigidity) via cytoskeletal conduits accurately predicted fluctuations in cell-matrix adhesion structures [116]. Taken together, these fibroblastic-ECM interactions constitute 
the SDR maintenance cycle that either retains the stroma environment in an innate homeostatic equilibrium or promotes a distinct desmoplastic stromal state/environment (Figures 2 \& 3).

This ECM-induced cytoskeletal rearrangement (i.e., conduit) is known to occur via Rho family small GTPases regulation and to participate in cell migration, polarization and differentiation [117-120]. Moreover, molecules involved in the regulation of Rho activity such as caveolin1 have been associated with desmoplastic and pro-metastatic architectural ECM rearrangements [14]. Recent evidence has shown that TGF- $\beta$-induced myofibroblastic (i.e., CAF) activation is dependent on Rho activity and nuclear translocation of Yes-associated protein-1 (YAP1). This TGF- $\beta$-mediated process is known to transcriptionally regulate proteins involved in proliferation and apoptosis which ultimately culminates in altered ECM production [121]. In fact, YAP has been shown to play a role in both ECM remodeling and in cellular responses to altered ECMs. Hence, in this context, YAP signaling constitutes a major regulator that both triggers and sustains CAF activity [54]. Moreover, changes in CAFs' secreted proteases (i.e MMPs) or matrix cross-linkers, such as lysyl oxidase, as well as cell-membrane tethered proteases like FAP [122] or CAF-secreted inflammatory matricellular and other components such as periostin $[123,124]$, osteonectin/SPARC, hyaluronic acid [125], tenascin-c [124] and Wnt-5a signaling [123], have all been shown to directly or indirectly modify ECM characteristics such as fiber anisotropy, stiffness and biochemical composition. These dynamic and reciprocal examples support the proposed premise conveyed in Figure 3 suggesting that diverse stromal equilibrium states are maintained during nonpathological conditions (i.e., innate stroma) or during temporary (acute) or sustained (chronic) injury, growth and/or other circumstances (e.g., neoplasia).

In support of these observations, investigators demonstrated that simple manipulation of the physical features of the ECM in vitro dramatically alters gene expression profiles and reprograms cellular phenotypes [126]. Similarly, CAF-induced ECM modifications, which incidentally show high anisotropic features in vitro, can activate naïve/innate fibroblasts overnight [29]. Additionally changes to the topographical and/or mechanical characteristics of substrates (i.e. acrylamide gels, hydrogels, etc.) also affect fibroblastic activation [54], which too depends on actin-generated Rho activity [127]. Thus, stiffness and serum factors contribute to the transition of innate stromal cells into an active (i.e., myofibroblastic) phenotype $[106,107,128]$. When considering the in vivo tumor microenvironment, the ECM is classically much stiffer than its innate counterpart. Typically the ECM is aligned in quantifiable organized type I collagen fiber patterns $[14,15,129,130]$. It also includes increased ECM cross-linking and fiber density [30,106,131-135].

Many studies have aimed to associate notable stromal phenotypic changes such as desmoplastic markers with clinical prognostics. For example, using predictors based on the CAF-to-collagen deposition ratio or type I collagen topographical (anisotropic) ECM features, investigators observed a correlation with unfavorable patient survival $[76,129,130,136-139]$. Others found that actin binding proteins such as palladin, which regulates stromal pro-metastatic CAF and desmoplastic ECM features (e.g., alignment) [140], can be used as a predictive marker of cancer recurrences subsequent to tumor surgical resection [137]. These types of microenvironmental reactions should be distinguished from tumor-restrictive stroma signatures [141] where, for example, increases in collagen deposition per se, in the absence of increased cellular $\alpha$-SMA levels, correlates with better patient outcome [76]. Similarly, innate type I collagen topographic signatures in which ECM fibers are isotropic (disorganized) were also determined to correlate with improved patient survival $[129,130]$. Overall, these findings suggest that increased isotropic-collagen ECM deposition in the absence of activated stromal cellular markers 
correlates with better patient outcomes. Collectively, these observations appear to provide rationale for ablating (or reprogramming) desmoplastic stroma as an effective means for tumor control.

\section{Restoration of innate stroma characteristics promises a feasible therapeutic strategy}

It is well known that the innate stromal environment is tumor suppressive $[3,7,16,67,142]$ and that the onset of desmoplasia disrupts its natural inhibitory role via induction of a new system that no longer restricts, and perhaps even supports, tumorigenic behaviors [68,82,143,144]. Therefore, it is logical to conclude that desmoplasia inspires tumor growth and metastasis, while it is known that it also confers immunosuppression [51] as well as chemo- and radiotherapy resistance due to massive ECM deposition $[85,145,146]$. With this in mind, targeting desmoplastic stroma appears to be a promising therapeutic approach for treating neoplasias that are rich in desmoplastic stroma (Figure 1) [57,146]. In line with this idea, researchers sought to decrease desmoplasia by eliminating activated stromal cells and/or pathways known to significantly contribute to disease onset and progression.

An attempt to interfere with stromal activation involved targeting the sonic hedgehog (Shh) pathway, which participates in several cellular processes such as stem cell maintenance, cell proliferation, differentiation and tissue polarity as well as desmoplastic induction $[147,148]$. Hence, constitutive activation of the Shh pathway is considered a common pro-tumorigenic event that has gained much attention as a potential therapeutic target. Indeed, inhibition of this pathway, either by targeting Shh ligand directly or its downstream effectors smoothened and gli1, decreases tumor growth and metastasis in a plethora of mouse models [146,148-151]. The role of Shh in tumor-stroma interactions via genetic deletion and long-term (i.e., chronic) pharmacologic Shh inhibition has also been examined. Although inhibition of the pathway indeed accomplished ablation of pancreatic fibrous stroma (i.e., desmoplasia), it unexpectedly accelerated undifferentiated tumor growth and vessel restoration perhaps due to loss of homeostatic SDR regulation in the tissue environment [64]. Accordingly, a clinical trial designed to chronically ablate Shh signaling in pancreatic cancer was prematurely terminated due to its detrimental effects in gemcitabine-Shh combinatorial treatment in comparison to gemcitabine alone [69].

Another approach aimed at negating desmoplastic production sought to target cells primarily responsible for its development: the $\alpha$-SMA positive CAFs. However, depletion of these cells resulted in increased immunosuppression and advanced tumor progression. After further investigation into patient cohorts and contrary to previous conclusions, it was determined that the accumulation of $\alpha$-SMA expressing CAFs correlates with improved patient outcomes [65].

When considering these results, it is critical to appreciate the role of the innate stroma in maintaining the tumor-restrictive homeostatic equilibrium via processes related to SDR. For example, removing or ablating key regulators of SDR's cyclic interplay may facilitate tumor progression by concomitantly and inadvertently removing the tumor-counteracting functions of SDR. Ideally, this scenario is reminiscent of an enzymatic reaction in which the addition of any catalyst that lowers the threshold of activation simultaneously accelerates the rate of the reaction. In comparison to this biological phenomenon, the destruction of SDR regulation dramatically increases tumorigenic features by decreasing innate tumor restrictive components. Hence, ablating this microenvironmental setting negates the proposed possibility of "shifting the homeostatic equilibrium" to restore innate stromal tumor-restrictive functions (Figure 3). 
In light of this rationale, shifting back the desmoplastic stromal system to a tumor-restrictive state could serve as a conceivable therapy. Simply put, restoring the effects that prevent tumor progression should, at minimum, serve as combinatorial therapeutics aimed at targeting the tumor while simultaneously reprogramming the stroma. These, together with novel immune checkpoint inhibitors that reinstate the natural anti-tumoral immune effects, should render the finest results, especially since desmoplasia is known to impart a pro-tumorigenic immunosuppressive microenvironment $[125,152]$.

Another study in pancreatic cancer aimed to eliminate the biophysical barriers created by desmoplastic stroma. The desmoplastic stroma is commonly thought to limit therapeutic perfusion via collapse of resident blood vessels due to apparently high interstitial pressure [153]. In this approach, the researchers explored the contentious role of the ECM component, hyaluronic acid (HA). HA is known to be abundantly expressed in dynamic processes such as embryogenesis and oncogenesis and has been linked to tumor-supportive roles involved in increasing metastatic potential in some instances while functioning as a tumor suppressor in others [154-157]. When investigators targeted HA via enzymatic degradation (using PEGPH20), which excitingly restored previously collapsed blood vessels by decreasing interstitial pressure (or as later suggested solid stress [158]), there was an improved response to gemcitabine treatment [153]. Interestingly, as treatment ceased, HA levels replenished which were speculated to be due to $\alpha$-SMA positive CAFs and ECM dynamics that notably drive HA expression. Nonetheless, the authors successfully demonstrated that the physical barrier imposed by the desmoplastic stroma can be overcome via enzymatic degradation of HA without supporting tumor growth [153]. Excitingly, this study served as basis for a phase-lb clinical trial [159] and, after overcoming some adverse drug thromboembolic events, it is currently being followed by additional trials in which PEGPH2O is to be added to front line drug combinations such as nab-paclitaxel/gemcitabine and more. In addition, more recently it was shown that HA targeting increases collagen and fibronectin deposition during fibroblastic activation in a (benign) way that may differ from the more common TGF- $\beta$ induction [157]. These results suggest that the subsequent ECM production may convey changes in de novo ECM production $[129,130]$. In accordance with this notion, researchers have demonstrated that anisotropic levels of collagen fibers observed in desmoplastic biopsies promotes metastatic breast and other cancers $[14,130,160]$, although isotropic ECM (disordered ECM arrangement) influences the effectiveness of chemotherapeutic treatments [160].

As mentioned previously, desmoplastic onset instigates an immune privileged (i.e., immunosuppressive) effect, which inhibits anti-tumoral T-cells from penetrating the stroma enough to reach the tumor [125]. This observation has been proposed to explain why, even though immune inhibitory checkpoints such as those impeding the Programmed Death-Ligand 1 (PD-L1) should facilitate an adequate immune reaction, these often fail to impart significant responses (i.e., in prominently desmoplastic-rich pancreatic cancer). As such, investigators targeted FAP and CXCL12/SDF1 expressing desmoplastic fibroblasts and were successful in reinstituting an effective anti tumoral T-cell penetration. In consequence, these two approaches were combined and demonstrated a synergistic effect in treating desmoplastic rich cancers such as in the case of pancreatic ductal adenocarcinoma [152].

During early cancer development, TGF- $\beta$ is established as a tumor suppressor. However, as the tumor progresses, it becomes refractory to TGF- $\beta$ suppression. When this occurs, the tumor milieu is gradually enriched in TGF- $\beta$ now instigating, as opposed to repressing, desmoplastic development and tumor progression $[161,162]$. In light of this, inhibition of TGF- $\beta$ has become an obvious strategy for targeting cancer. Inhibition of TGF- $\beta$ is being developed via various strategies such as obstructing ligand or 
receptor binding and/or blocking TGF- $\beta$ downstream effectors [161,162]. Nonetheless, a number of preclinical concerns became evident when hemorrhagic, degenerative and inflammatory lesions developed due to either high dosage or continuous TGF- $\beta$ inhibitory treatments. Hence, intermittent low dosages were successful at the preclinical setting, which served as basis for designing clinical trials [163]. In fact, some of these drugs were demonstrated to be safe using specific dosage regimens and have proceeded into phase II and III clinical trials while others are still in preclinical development (i.e., Trabedersen [164-167] and Galunisertib [168-172]). Studies attempting to inhibit TGF- $\beta$ function suggested that understanding and monitoring the long-term effects associated with targeting this pathway are crucial in effectively combating cancer progression and possibly even preventing its development.

Another approach designed to overcome desmoplasia involved transcriptional reprogramming of desmoplastic processes by stabilizing the Vitamin D receptor (VDR) [173]. VDR is cited as the master regulator of the genomic-driven activation of fibroblasts, although its inhibition has been suggested to re-sensitize pancreatic cancer cells that became resistant to gemcitabine [174]. In any case, VDR activation achieves stromal restoration by inhibiting the TGF- $\beta / S$ mad pathway that, as previously discussed, constitutes a key driver of fibroblastic activation $[125,173,175]$. With the goal of ramping up the activity of VDR, investigators introduced an analog of its ligand, which resulted in the suppression of inflammatory cytokines and growth factors, enhanced angiogenesis, and increased efficacy of therapeutics while significantly improving overall survival [176]. Together these studies reinforce the feasibility of stromal remodeling and serve as premises behind several planned and ongoing clinical trials $[177,178]$.

\section{Conclusion}

Evolutionarily, the body is physiologically conditioned to address and resolve insults that prompt temporary deviations from innate tissue functions through both local and systemic repair processes. These temporary occurrences are typically ended when the acutely altered SDR is reverted back to an innate SDR equilibrium. Nonetheless, when environmental insults such as cancer or chronic fibrosis persist, the acute SDR balance is "shifted" towards a new equilibrium as seen in desmoplastic SDR. This pathological adaptation favors (or permits) the aggressive nature of the disease state whereas ablation of compensatory elements in the stroma impairs the possibility of restoring an innate tumor-restrictive status (Figure 3). Similar concepts have been proposed in conditions involving dormant viruses, such as HSV-1, that become re-activated once the threshold for viral tolerance is lowered (i.e physiological and physical changes, immunosuppression, etc.) [179]. Additionally, this notion is conceptualized in circumstances in which SDR processes are lowered/altered such that communal bacteria or yeast are permitted to overtake the host microenvironment [180-183]. In both cases, therapeutic options that restore and maintain the environmental balance of an innate system are most effective in both treatment and prevention of disease progression [179,182-185]. The evidence provided within this review collectively points to a similar adage in cancer in which our limited understanding of balancing SDR interplay impedes substantial advances in current therapies. Thus, a thorough understanding of key regulatory components that influence the balance of SDR processes (Figure 3) will surely provide improved therapeutic strategies, and perhaps even preventive therapies to effectively treat cancer, as well as its accompanying microenvironmental components.

\section{Acknowledgments}


First, we would like to acknowledge and apologize to our numerous colleagues whose studies we could not cite due to space limitations. Also, we thank S. Grivennikov, S, Sykes, R. Francescone, J. FrancoBarraza and K. Persaud for comments, E. Ragan for proofreading and P. Ovseiovich for graphic design.

We gratefully recognize support by, DOD W81XH-15-1-0170 (EC), NIH/NCI R01 CA113451-09 (EC) and R01 CA113451-09S1 (JA/EC) as well as NIH/NCl core grant CA06927 in support of Fox Chase Cancer Center's facilities (i.e., Talbot Library). We would like to recognize funds from the Commonwealth of Pennsylvania and kind gifts from Mrs. Concetta Greenberg in honor of her late husband Marvin S. Greenberg (EC) and Bucks County Board of Associates (EC) in support of Fox Chase Cancer Center's Pancreatic Cancer Research.

\section{References and recommended reading}

Papers of particular interest have been highlighted as:

* of special interest

** of outstanding interest

1. Langhans T: Pulsirende cavernoese Geschwulst der Miltz mit metastatischen Knoten in der Leber. Virchows Archiv 1879, 75:273-291.

2. Paget S: The distribution of secondary growths in cancer of the breast. The Lancet 1889, 133:571573.

3. Rybinski B, Franco-Barraza J, Cukierman E: The wound healing, chronic fibrosis, and cancer progression triad. Physiol Genomics 2014, 46:223-244.

4. Cammarota F, Laukkanen MO: Mesenchymal stem/stromal cells in stromal evolution and cancer progression. Stem Cells Int 2016, 2016:4824573.

5. Tarin D: Clinical and biological implications of the tumor microenvironment. Cancer Microenviron 2012, 5:95-112.

* 6. Naba A, Clauser KR, Ding H, Whittaker CA, Carr SA, Hynes RO: The extracellular matrix: Tools and insights for the "omics" era. Matrix Biol 2016, 49:10-24.

* Comprehensive review describing and anotating "the matrisome."

7. Beacham DA, Cukierman E: Stromagenesis: the changing face of fibroblastic microenvironments during tumor progression. Semin Cancer Biol 2005, 15:329-341.

8. Bhowmick NA, Neilson EG, Moses HL: Stromal fibroblasts in cancer initiation and progression. Nature 2004, 432:332-337.

9. Chu GC, Kimmelman AC, Hezel AF, DePinho RA: Stromal biology of pancreatic cancer. J Cell Biochem 2007, 101:887-907.

10. Kunz-Schughart LA, Knuechel R: Tumor-associated fibroblasts (part I): Active stromal participants in tumor development and progression? Histol Histopathol 2002, 17:599-621.

11. Hu M, Polyak K: Microenvironmental regulation of cancer development. Curr Opin Genet Dev 2008, 18:27-34.

12. Lakhani S, Bissell M: Introduction: the role of myoepithelial cells in integration of form and function in the mammary gland. J Mammary Gland Biol Neoplasia 2005, 10:197-198.

13. de Jong KP, von Geusau BA, Rottier CA, Bijzet J, Limburg PC, de Vries EG, Fidler V, Slooff MJ: Serum response of hepatocyte growth factor, insulin-like growth factor-I, interleukin-6, and acute phase proteins in patients with colorectal liver metastases treated with partial hepatectomy or cryosurgery. J Hepatol 2001, 34:422-427. 
** 14. Goetz JG, Minguet S, Navarro-Lerida I, R JJL, Samaniego R, Calvo E, Tello M, Osteso-Ibanez T, Pellinen $T$, Echarri A, et al.: Biomechanical remodeling of the microenvironment by stromal caveolin-1 favors tumor invasion and metastasis. Cell 2011, 146:148-163.

** This study demonstrated how biomechanical manipulations of the stroma, which depend on mechanisms that regulate stromal cytoskeletal conduits, result in altered metastatic outcomes.

15. Provenzano PP, Eliceiri KW, Campbell JM, Inman DR, White JG, Keely PJ: Collagen reorganization at the tumor-stromal interface facilitates local invasion. BMC Med 2006, 4:38.

16. Mintz B, Illmensee K: Normal genetically mosaic mice produced from malignant teratocarcinoma cells. Proc Natl Acad Sci U S A 1975, 72:3585-3589.

17. Hotary KB, Allen ED, Brooks PC, Datta NS, Long MW, Weiss SJ: Membrane type i matrix metalloproteinase usurps tumor growth control imposed by the three-dimensional extracellular matrix. Cell 2003, 114:33-45.

18. Barcellos-Hoff MH, Ravani SA: Irradiated mammary gland stroma promotes the expression of tumorigenic potential by unirradiated epithelial cells. Cancer Res 2000, 60:1254-1260.

19. Maffini MV, Soto AM, Calabro JM, Ucci AA, Sonnenschein C: The stroma as a crucial target in rat mammary gland carcinogenesis. J Cell Sci 2004, 117:1495-1502.

20. Xu R, Boudreau A, Bissell MJ: Tissue architecture and function: dynamic reciprocity via extra- and intra-cellular matrices. Cancer Metastasis Rev 2009, 28:167-176.

21. Schultz GS, Davidson JM, Kirsner RS, Bornstein P, Herman IM: Dynamic reciprocity in the wound microenvironment. Wound Repair Regen 2011, 19:134-148.

22. Thorne JT, Segal TR, Chang S, Jorge S, Segars JH, Leppert PC: Dynamic reciprocity between cells and their microenvironment in reproduction. Biol Reprod 2015, 92:25.

23. Werb Z, Chin JR: Extracellular matrix remodeling during morphogenesis. Ann N Y Acad Sci 1998, 857:110-118.

24. Nelson CM, Bissell MJ: Of extracellular matrix, scaffolds, and signaling: tissue architecture regulates development, homeostasis, and cancer. Annu Rev Cell Dev Biol 2006, 22:287-309.

25. Dvorak HF: Tumors: wounds that do not heal. Similarities between tumor stroma generation and wound healing. N Eng/ J Med 1986, 315:1650-1659.

26. Schafer M, Werner S: Cancer as an overhealing wound: an old hypothesis revisited. Nat Rev Mol Cell Biol 2008, 9:628-638.

27. Bissell MJ, Rizki A, Mian IS: Tissue architecture: the ultimate regulator of breast epithelial function. Curr Opin Cell Biol 2003, 15:753-762.

28. Hagios $C$, Lochter $A$, Bissell MJ: Tissue architecture: the ultimate regulator of epithelial function? Philos Trans R Soc Lond B Biol Sci 1998, 353:857-870.

29. Amatangelo MD, Bassi DE, Klein-Szanto AJ, Cukierman E: Stroma-derived three-dimensional matrices are necessary and sufficient to promote desmoplastic differentiation of normal fibroblasts. Am J Pathol 2005, 167:475-488.

30. Paszek MJ, Zahir N, Johnson KR, Lakins JN, Rozenberg GI, Gefen A, Reinhart-King CA, Margulies SS, Dembo M, Boettiger $\mathrm{D}$, et al.: Tensional homeostasis and the malignant phenotype. Cancer Cell 2005, 8:241-254.

31. Bhowmick NA, Moses HL: Tumor-stroma interactions. Curr Opin Genet Dev 2005, 15:97-101.

32. Togo S, Shimada H, Kubota $T$, Moossa AR, Hoffman RM: Host organ specifically determines cancer progression. Cancer Res 1995, 55:681-684.

33. Tuxhorn JA, Ayala GE, Smith MJ, Smith VC, Dang TD, Rowley DR: Reactive stroma in human prostate cancer: induction of myofibroblast phenotype and extracellular matrix remodeling. Clin Cancer Res 2002, 8:2912-2923.

34. Kunz-Schughart LA, Knuechel R: Tumor-associated fibroblasts (part II): Functional impact on tumor tissue. Histol Histopathol 2002, 17:623-637. 
35. Tuxhorn JA, Ayala GE, Rowley DR: Reactive stroma in prostate cancer progression. J Urol 2001, 166:2472-2483.

36. Li G, Satyamoorthy K, Meier F, Berking C, Bogenrieder T, Herlyn M: Function and regulation of melanoma-stromal fibroblast interactions: when seeds meet soil. Oncogene 2003, 22:31623171.

37. Desmouliere A, Guyot C, Gabbiani G: The stroma reaction myofibroblast: a key player in the control of tumor cell behavior. Int J Dev Biol 2004, 48:509-517.

38. Olumi AF, Grossfeld GD, Hayward SW, Carroll PR, Tlsty TD, Cunha GR: Carcinoma-associated fibroblasts direct tumor progression of initiated human prostatic epithelium. Cancer Res 1999, 59:5002-5011.

39. Bissell MJ, Hall HG, Parry G: How does the extracellular matrix direct gene expression? J Theor Biol 1982, 99:31-68.

40. Hynes RO: The extracellular matrix: not just pretty fibrils. Science 2009, 326:1216-1219.

41. Tamkun JW, DeSimone DW, Fonda D, Patel RS, Buck C, Horwitz AF, Hynes RO: Structure of integrin, a glycoprotein involved in the transmembrane linkage between fibronectin and actin. Cell 1986, 46:271-282.

42. Berrier AL, Yamada KM: Cell-matrix adhesion. J Cell Physiol 2007, 213:565-573.

43. Jahed Z, Shams H, Mehrbod M, Mofrad MRK: Chapter Five - Mechanotransduction pathways linking the extracellular matrix to the nucleus. In International Review of Cell and Molecular Biology. Edited by Kwang WJ: Academic Press; 2014:171-220. vol Volume 310.]

44. Connor Y, Tekleab S, Nandakumar S, Walls C, Tekleab Y, Husain A, Gadish O, Sabbisetti V, Kaushik S, Sehrawat $S$, et al.: Physical nanoscale conduit-mediated communication between tumour cells and the endothelium modulates endothelial phenotype. Nat Commun 2015, 6:8671.

45. Maniotis AJ, Chen CS, Ingber DE: Demonstration of mechanical connections between integrins, cytoskeletal filaments, and nucleoplasm that stabilize nuclear structure. Proc Natl Acad Sci U S A 1997, 94:849-854.

46. Ingber DE: Tensegrity I. Cell structure and hierarchical systems biology. J Cell Sci 2003, 116:11571173.

47. Ingber DE: Tensegrity II. How structural networks influence cellular information processing networks. J Cell Sci 2003, 116:1397-1408.

48. Tadeo I, Berbegall AP, Escudero LM, Álvaro T, Noguera R: Biotensegrity of the extracellular matrix: physiology, dynamic mechanical balance and implications in oncology and mechanotherapy. Frontiers in Oncology 2014, 4:39.

49. Anderson AR, Weaver AM, Cummings PT, Quaranta V: Tumor morphology and phenotypic evolution driven by selective pressure from the microenvironment. Cell 2006, 127:905-915.

50. Desmouliere A: Factors influencing myofibroblast differentiation during wound healing and fibrosis. Cell Biol Int 1995, 19:471-476.

51. Ribas A: Adaptive Immune Resistance: How Cancer Protects from Immune Attack. Cancer Discovery 2015, 5:915-919.

52. Hinz B: Myofibroblasts. Exp Eye Res 2016, 142:56-70.

53. Öhlund D, Elyada E, Tuveson D: Fibroblast heterogeneity in the cancer wound. The Journal of Experimental Medicine 2014, 211:1503-1523.

54. Calvo F, Ege N, Grande-Garcia A, Hooper S, Jenkins RP, Chaudhry SI, Harrington K, Williamson P, Moeendarbary E, Charras G, et al.: Mechanotransduction and YAP-dependent matrix remodelling is required for the generation and maintenance of cancer-associated fibroblasts. Nat Cell Biol 2013, 15:637-646.

55. Malek A, Bakhidze E, Noske A, Sers C, Aigner A, Schafer R, Tchernitsa O: HMGA2 gene is a promising target for ovarian cancer silencing therapy. Int J Cancer 2008, 123:348-356. 
56. Witte MB, Barbul A: General principles of wound healing. Surg Clin North Am 1997, 77:509-528.

57. Engels B, Rowley DA, Schreiber H: Targeting stroma to treat cancers. Semin Cancer Biol 2012, 22:4149.

58. Tlsty TD, Coussens LM: Tumor stroma and regulation of cancer development. Annu Rev Pathol 2006, 1:119-150.

59. Barcellos-Hoff MH: New biological insights on the link between radiation exposure and breast cancer risk. J Mammary Gland Biol Neoplasia 2013, 18:3-13.

60. Malik R, Lelkes PI, Cukierman E: Biomechanical and biochemical remodeling of stromal extracellular matrix in cancer. Trends Biotechnol 2015, 33:230-236.

61. McConnell JC, O'Connell OV, Brennan K, Weiping L, Howe M, Joseph L, Knight D, O'Cualain R, Lim Y, Leek $A$, et al.: Increased peri-ductal collagen micro-organization may contribute to raised mammographic density. Breast Cancer Res 2016, 18:5.

62. Jodele S, Blavier L, Yoon JM, DeClerck YA: Modifying the soil to affect the seed: role of stromalderived matrix metalloproteinases in cancer progression. Cancer Metastasis Rev 2006, 25:3543.

63. Ohuchida K, Mizumoto K, Murakami M, Qian LW, Sato N, Nagai E, Matsumoto K, Nakamura T, Tanaka M: Radiation to stromal fibroblasts increases invasiveness of pancreatic cancer cells through tumor-stromal interactions. Cancer Res 2004, 64:3215-3222.

** 64. Rhim AD, Oberstein PE, Thomas DH, Mirek ET, Palermo CF, Sastra SA, Dekleva EN, Saunders T, Becerra CP, Tattersall IW, et al.: Stromal elements act to restrain, rather than support, pancreatic ductal adenocarcinoma. Cancer Cell 2014, 25:735-747.

** Study proposes that some aspects of reactive stroma suppress tumorigenesis which explains why, following its ablation (under constant genetic or chemical Shh pathway inhibition), tumors become increasingly aggressive. The study concluded that Shh plays a role in angiogenic inhibition. See also \#65.

** 65. Ozdemir BC, Pentcheva-Hoang T, Carstens JL, Zheng X, Wu CC, Simpson TR, Laklai H, Sugimoto H, Kahlert C, Novitskiy SV, et al.: Depletion of carcinoma-associated fibroblasts and fibrosis induces immunosuppression and accelerates pancreas cancer with reduced survival. Cancer Cell 2014, 25:719-734.

** This article also highlights the tumor-restrictive aspect of the fibrotic reaction that is associated with pancreatic cancer. In this study $\alpha$-SMA positive cells were genetically depleted, which rendered tumors increasingly aggressive but also more susceptible to anti-CTLA4 immunotherapy. See also \#64.

66. Bauer G: Elimination of transformed cells by normal cells: a novel concept for the control of carcinogenesis. Histol Histopathol 1996, 11:237-255.

** 67. Bissell MJ, Hines WC: Why don't we get more cancer? A proposed role of the microenvironment in restraining cancer progression. Nat Med 2011, 17:320-329.

** This review highlights the restrictive nature of the stroma environment in patients with notable cancer mutations that did not manifest. The authors attribute this restraint of cancer growth to the stromal environment as an active participant.

68. Sadlonova A, Novak Z, Johnson MR, Bowe DB, Gault SR, Page GP, Thottassery JV, Welch DR, Frost AR: Breast fibroblasts modulate epithelial cell proliferation in three-dimensional in vitro coculture. Breast Cancer Res 2005, 7:R46-59.

69. Lang M: Infinity Pharma halts pancreatic cancer trial. In Boston Busines journal. Edited by journal BB. USA; 2012.

70. Hinz B, Gabbiani G: Mechanisms of force generation and transmission by myofibroblasts. Curr Opin Biotechnol 2003, 14:538-546. 
71. Montesano R, Orci L: Transforming growth factor beta stimulates collagen-matrix contraction by fibroblasts: implications for wound healing. Proc Natl Acad Sci U S A 1988, 85:4894-4897.

72. Hinz B, Phan SH, Thannickal VJ, Prunotto M, Desmouliere A, Varga J, De Wever O, Mareel M, Gabbiani G: Recent developments in myofibroblast biology: paradigms for connective tissue remodeling. Am J Pathol 2012, 180:1340-1355.

73. Sugimoto $H$, Mundel TM, Kieran MW, Kalluri R: Identification of fibroblast heterogeneity in the tumor microenvironment. Cancer Biol Ther 2006, 5:1640-1646.

* 74. Park SY, Kim HM, Koo JS: Differential expression of cancer-associated fibroblast-related proteins according to molecular subtype and stromal histology in breast cancer. Breast Cancer Res Treat 2015, 149:727-741.

* This study suggests that discrete fibroblastic stroma protein signatures could serve as future prognostic predictors and perhaps also as potential therapeutic targets.

75. Yazhou C, Wenlv S, Weidong Z, Licun W: Clinicopathological significance of stromal myofibroblasts in invasive ductal carcinoma of the breast. Tumour Biol 2004, 25:290-295.

76. Erkan M, Michalski CW, Rieder S, Reiser-Erkan C, Abiatari I, Kolb A, Giese NA, Esposito I, Friess H, Kleeff $\mathrm{J}$ : The activated stroma index is a novel and independent prognostic marker in pancreatic ductal adenocarcinoma. Clin Gastroenterol Hepatol 2008, 6:1155-1161.

77. Barlow J, Yandell D, Weaver D, Casey T, Plaut K: Higher stromal expression of transforming growth factor-beta type II receptors is associated with poorer prognosis breast tumors. Breast Cancer Res Treat 2003, 79:149-159.

78. Kheradmand F, Werner E, Tremble $P$, Symons $M$, Werb Z: Role of Rac1 and oxygen radicals in collagenase-1 expression induced by cell shape change. Science 1998, 280:898-902.

79. Baneyx G, Baugh L, Vogel V: Fibronectin extension and unfolding within cell matrix fibrils controlled by cytoskeletal tension. Proc Natl Acad Sci U S A 2002, 99:5139-5143.

80. Feral CC, Zijlstra A, Tkachenko E, Prager G, Gardel ML, Slepak M, Ginsberg MH: CD98hc (SLC3A2) participates in fibronectin matrix assembly by mediating integrin signaling. J Cell Biol 2007, 178:701-711.

81. Lambert CA, Colige AC, Munaut C, Lapiere CM, Nusgens BV: Distinct pathways in the overexpression of matrix metalloproteinases in human fibroblasts by relaxation of mechanical tension. Matrix Biol 2001, 20:397-408.

82. Farrow $B$, Albo D, Berger DH: The role of the tumor microenvironment in the progression of pancreatic cancer. J Surg Res 2008, 149:319-328.

83. Kuwahara K, Kinoshita H, Kuwabara Y, Nakagawa Y, Usami S, Minami T, Yamada Y, Fujiwara M, Nakao K: Myocardin-related transcription factor $A$ is a common mediator of mechanical stressand neurohumoral stimulation-induced cardiac hypertrophic signaling leading to activation of brain natriuretic peptide gene expression. Mol Cell Biol 2010, 30:4134-4148.

84. Crider BJ, Risinger GM, Jr., Haaksma CJ, Howard EW, Tomasek JJ: Myocardin-related transcription factors $A$ and $B$ are key regulators of TGF-beta1-induced fibroblast to myofibroblast differentiation. J Invest Dermatol 2011, 131:2378-2385.

85. Hwang RF, Moore T, Arumugam T, Ramachandran V, Amos KD, Rivera A, Ji B, Evans DB, Logsdon CD: Cancer-associated stromal fibroblasts promote pancreatic tumor progression. Cancer Res 2008, 68:918-926.

86. Kikuta K, Masamune A, Watanabe T, Ariga H, Itoh H, Hamada S, Satoh K, Egawa S, Unno M, Shimosegawa T: Pancreatic stellate cells promote epithelial-mesenchymal transition in pancreatic cancer cells. Biochem Biophys Res Commun 2010, 403:380-384.

87. Rasanen K, Vaheri A: Activation of fibroblasts in cancer stroma. Exp Cell Res 2010, 316:2713-2722.

88. Orimo A, Weinberg RA: Stromal fibroblasts in cancer: a novel tumor-promoting cell type. Cell Cycle 2006, 5:1597-1601. 
89. Jiang L, Gonda TA, Gamble MV, Salas M, Seshan V, Tu S, Twaddell WS, Hegyi P, Lazar G, Steele I, et al.: Global hypomethylation of genomic DNA in cancer-associated myofibroblasts. Cancer Res 2008, 68:9900-9908.

90. Vizoso M, Esteller M: DNA methylation plasticity contributes to the natural history of metastasis. Cell Cycle 2015, 14:2863-2864.

91. Hanson JA, Gillespie JW, Grover A, Tangrea MA, Chuaqui RF, Emmert-Buck MR, Tangrea JA, Libutti SK, Linehan WM, Woodson KG: Gene promoter methylation in prostate tumor-associated stromal cells. J Natl Cancer Inst 2006, 98:255-261.

* 92. Vizoso M, Puig M, Carmona FJ, Maqueda M, Velasquez A, Gomez A, Labernadie A, Lugo R, Gabasa $M$, Rigat-Brugarolas $L G$, et al.: Aberrant DNA methylation in non-small cell lung cancerassociated fibroblasts. Carcinogenesis 2015, 36:1453-1463.

* This manuscript links alterations in chromatin structure and dynamics maintaining CAF phenotypes. Findings support previous reports proposing that sustained CAF phenotypes are necessary for tumor-permissive ECM remodeling.

93. Hu M, Yao J, Cai L, Bachman KE, van den Brule F, Velculescu V, Polyak K: Distinct epigenetic changes in the stromal cells of breast cancers. Nat Genet 2005, 37:899-905.

94. Berndt A, Kosmehl H, Mandel U, Gabler U, Luo X, Celeda D, Zardi L, Katenkamp D: TGF beta and bFGF synthesis and localization in Dupuytren's disease (nodular palmar fibromatosis) relative to cellular activity, myofibroblast phenotype and oncofetal variants of fibronectin. Histochem J 1995, 27:1014-1020.

95. Dugina V, Fontao L, Chaponnier C, Vasiliev J, Gabbiani G: Focal adhesion features during myofibroblastic differentiation are controlled by intracellular and extracellular factors. J. Cell Sci. 2001, 114:3285-3296.

* 96. Webber JP, Spary LK, Sanders AJ, Chowdhury R, Jiang WG, Steadman R, Wymant J, Jones AT, Kynaston $\mathrm{H}$, Mason MD, et al.: Differentiation of tumour-promoting stromal myofibroblasts by cancer exosomes. Oncogene 2015, 34:290-302.

* Article demonstrates how carcinoma cells drive stroma cell fibroblastic activation via TGF- $\beta$ tumor-exosomal cargo, which differs from soluble TGF- $\beta$ activation. Targeting these cancer secreted exosomes appreciably decreases desmoplastic activation as well as the ability of cancer cells to promote tumor-associated stromal features.

97. Hinz B: The extracellular matrix and transforming growth factor-beta1: Tale of a strained relationship. Matrix Biol 2015, 47:54-65.

98. Kubow KE, Klotzsch E, Smith ML, Gourdon D, Little WC, Vogel V: Crosslinking of cell-derived 3D scaffolds up-regulates the stretching and unfolding of new extracellular matrix assembled by reseeded cells. Integrative Biology 2009, 1:635-648.

99. Krammer A, Craig D, Thomas WE, Schulten K, Vogel V: A structural model for force regulated integrin binding to fibronectin's RGD-synergy site. Matrix Biology 2002, 21:139-147.

100. Vogel V: Mechanotransduction involving multimodular proteins: converting force into biochemical signals. Annu Rev Biophys Biomol Struct 2006, 35:459-488.

101. Shinde AV, Kelsh R, Peters JH, Sekiguchi K, Van De Water L, McKeown-Longo PJ: The alpha4beta1 integrin and the EDA domain of fibronectin regulate a profibrotic phenotype in dermal fibroblasts. Matrix Biol 2015, 41:26-35.

102. Klingberg F, Chow ML, Koehler A, Boo S, Buscemi L, Quinn TM, Costell M, Alman BA, Genot E, Hinz $B$ : Prestress in the extracellular matrix sensitizes latent TGF-beta1 for activation. J Cell Biol 2014, 207:283-297.

103. Li B, Moshfegh C, Lin Z, Albuschies J, Vogel V: Mesenchymal stem cells exploit extracellular matrix as mechanotransducer. Sci. Rep. 2013, 3. 
104. Freedman BR, Bade ND, Riggin CN, Zhang S, Haines PG, Ong KL, Janmey PA: The (dys)functional extracellular matrix. Biochim Biophys Acta 2015, 1853:3153-3164.

105. Wells RG: The role of matrix stiffness in regulating cell behavior. Hepatology 2008, 47:1394-1400.

* 106. McLane JS, Ligon LA: Palladin mediates stiffness-induced fibroblast activation in the tumor microenvironment. Biophys J 2015, 109:249-264.

* The authors of this manuscript highlight the importance of cytoskeletal reorganization during TGF- $\beta$ driven fibroblastic activation. This article suggests that ECM characteristics, such as increases in matrix stiffness, are influenced by cytoskeletal organizing proteins.

107. Chiquet M, Gelman L, Lutz R, Maier S: From mechanotransduction to extracellular matrix gene expression in fibroblasts. Biochim Biophys Acta 2009, 1793:911-920.

108. Chiquet $M$, Renedo AS, Huber F, Fluck M: How do fibroblasts translate mechanical signals into changes in extracellular matrix production? Matrix Biol 2003, 22:73-80.

109. Provenzano PP, Inman DR, Eliceiri KW, Keely PJ: Matrix density-induced mechanoregulation of breast cell phenotype, signaling and gene expression through a FAK-ERK linkage. Oncogene 2009, 28:4326-4343.

110. Chaudhuri O, Koshy ST, Branco da Cunha C, Shin JW, Verbeke CS, Allison KH, Mooney DJ: Extracellular matrix stiffness and composition jointly regulate the induction of malignant phenotypes in mammary epithelium. Nat Mater 2014, 13:970-978.

111. Hinz B, Gabbiani G, Chaponnier C: The NH2-terminal peptide of alpha-smooth muscle actin inhibits force generation by the myofibroblast in vitro and in vivo. $J$ Cell Biol 2002, 157:657663.

112. Ghosh K, Ingber DE: Micromechanical control of cell and tissue development: implications for tissue engineering. Adv Drug Deliv Rev 2007, 59:1306-1318.

113. Balaban NQ, Schwarz US, Riveline D, Goichberg P, Tzur G, Sabanay I, Mahalu D, Safran S, Bershadsky A, Addadi L, et al.: Force and focal adhesion assembly: a close relationship studied using elastic micropatterned substrates. Nat Cell Biol 2001, 3:466-472.

114. Geiger B, Bershadsky A, Pankov R, Yamada KM: Transmembrane crosstalk between the extracellular matrix--cytoskeleton crosstalk. Nat Rev Mol Cell Biol 2001, 2:793-805.

115. Geiger B, Bershadsky A: Assembly and mechanosensory function of focal contacts. Curr Opin Cell Biol 2001, 13:584-592.

* 116. Cao X, Lin Y, Driscoll TP, Franco-Barraza J, Cukierman E, Mauck RL, Shenoy VB: A chemomechanical model of matrix and nuclear rigidity regulation of focal adhesion size. Biophys J 2015, 109:1807-1817.

* This article presents a mathematical model explaining the relationship between intracellular and extracellular cues that both drive cellular contractions and control size and numbers of adhesion structures.

117. Liu H, Radisky DC, Wang F, Bissell MJ: Polarity and proliferation are controlled by distinct signaling pathways downstream of PI3-kinase in breast epithelial tumor cells. J Cell Biol 2004, 164:603612.

118. Akhtar N, Streuli CH: Rac1 links integrin-mediated adhesion to the control of lactational differentiation in mammary epithelia. J Cell Biol 2006, 173:781-793.

119. Jou TS, Nelson WJ: Effects of regulated expression of mutant RhoA and Rac1 small GTPases on the development of epithelial (MDCK) cell polarity. J Cell Biol 1998, 142:85-100.

120. Jaffe $A B$, Hall $A$, Schmidt A: Association of CNK1 with Rho guanine nucleotide exchange factors controls signaling specificity downstream of Rho. Curr Biol 2005, 15:405-412.

121. Piersma B, de Rond S, Werker PMN, Boo S, Hinz B, van Beuge MM, Bank RA: YAP1 is a driver of myofibroblast differentiation in normal and diseased fibroblasts. The American Journal of Pathology 2015, 185:3326-3337. 
122. Lee H-O, Mullins SR, Franco-Barraza J, Valianou M, Cukierman E, Cheng JD: FAP-overexpressing fibroblasts produce an extracellular matrix that enhances invasive velocity and directionality of pancreatic cancer cells. BMC Cancer 2011, 11:245.

123. Rashid ST, Humphries JD, Byron A, Dhar A, Askari JA, Selley JN, Knight D, Goldin RD, Thursz M, Humphries M: Proteomic analysis of extracellular matrix from the hepatic stellate cell line LX-2 identifies CYR61 and Wnt-5a as novel constituents of fibrotic liver. Journal of Proteome Research 2012.

124. Kii I, Nishiyama T, Li M, Matsumoto K, Saito M, Amizuka N, Kudo A: Incorporation of tenascin-C into the extracellular matrix by periostin underlies an extracellular meshwork architecture. $J$ Biol Chem 2010, 285:2028-2039.

125. Stromnes IM, DelGiorno KE, Greenberg PD, Hingorani SR: Stromal reengineering to treat pancreas cancer. Carcinogenesis 2014, 35:1451-1460.

126. Engler AJ, Sen S, Sweeney HL, Discher DE: Matrix elasticity directs stem cell lineage specification. Cell 2006, 126:677-689.

127. Huang X, Yang N, Fiore VF, Barker TH, Sun Y, Morris SW, Ding Q, Thannickal VJ, Zhou Y: Matrix stiffness-induced myofibroblast differentiation is mediated by intrinsic mechanotransduction. Am J Respir Cell Mol Biol 2012, 47:340-348.

128. Carracedo S, Lu N, Popova SN, Jonsson R, Eckes B, Gullberg D: The fibroblast integrin alpha11beta1 is induced in a mechanosensitive manner involving activin $A$ and regulates myofibroblast differentiation. J Biol Chem 2010, 285:10434-10445.

** 129. Bredfeldt JS, Liu Y, Conklin MW, Keely PJ, Mackie TR, Eliceiri KW: Automated quantification of aligned collagen for human breast carcinoma prognosis. J Pathol Inform 2014, 5:28.

** This manuscript established a measurable system that takes advantage of the prognostic value of tumor associated collagen signatures to provide consistent scoring among large patient populations. The study highlights the benefit in identifying appreciable ECM alterations for predicting patient survival.

130. Conklin MW, Eickhoff JC, Riching KM, Pehlke CA, Eliceiri KW, Provenzano PP, Friedl A, Keely PJ: Aligned collagen is a prognostic signature for survival in human breast carcinoma. The American Journal of Pathology 2011, 178:1221-1232.

131. Narani N, Arora PD, Lew A, Luo L, Glogauer M, Ganss B, McCulloch CA: Transforming growth factorbeta induction of alpha-smooth muscle actin is dependent on the deformability of the collagen matrix. Curr Top Pathol 1999, 93:47-60.

132. Chia HN, Vigen M, Kasko AM: Effect of substrate stiffness on pulmonary fibroblast activation by TGF-beta. Acta Biomater 2012, 8:2602-2611.

133. Hinz B, Mastrangelo D, Iselin CE, Chaponnier C, Gabbiani G: Mechanical tension controls granulation tissue contractile activity and myofibroblast differentiation. Am J Pathol 2001, 159:1009-1020.

134. Tomasek JJ, Haaksma CJ, Eddy RJ, Vaughan MB: Fibroblast contraction occurs on release of tension in attached collagen lattices: dependency on an organized actin cytoskeleton and serum. Anat $\operatorname{Rec}$ 1992, 232:359-368.

135. Tomasek JJ, Gabbiani G, Hinz B, Chaponnier C, Brown RA: Myofibroblasts and mechano-regulation of connective tissue remodelling. Nat Rev Mol Cell Biol 2002, 3:349-363.

136. Bacac M, Provero P, Mayran N, Stehle JC, Fusco C, Stamenkovic I: A mouse stromal response to tumor invasion predicts prostate and breast cancer patient survival. PLoS One 2006, 1:e32.

137. Gupta V, Bassi DE, Simons JD, Devarajan K, Al-Saleem T, Uzzo RG, Cukierman E: Elevated expression of stromal palladin predicts poor clinical outcome in renal cell carcinoma. PLoS One 2011, 6:e21494. 
** 138. Park JH, McMillan DC, Powell AG, Richards CH, Horgan PG, Edwards J, Roxburgh CSD: Evaluation of a tumor microenvironment-based prognostic score in primary operable colorectal cancer. Clinical Cancer Research 2015, 21:882-888.

** This article highlights the need of an established prognostic score based on tumor microenvironment features in a effort to stratify colorectal patients for potentially curative resection.

139. Isella C, Terrasi A, Bellomo SE, Petti C, Galatola G, Muratore A, Mellano A, Senetta R, Cassenti A, Sonetto C, et al.: Stromal contribution to the colorectal cancer transcriptome. Nat Genet 2015.

** 140. Goicoechea SM, Garcia-Mata R, Staub J, Valdivia A, Sharek L, McCulloch CG, Hwang RF, Urrutia $\mathrm{R}$, Yeh JJ, Kim HJ, et al.: Palladin promotes invasion of pancreatic cancer cells by enhancing invadopodia formation in cancer-associated fibroblasts. Oncogene 2014, 33:1265-1273. ** This manuscript highlights the pivotal role that CAFs' cytoskeletal remodeling (i.e., cytoskeletal conduit) plays in promoting pancreatic cancer invasion.

141. Bijlsma MF, van Laarhoven HW: The conflicting roles of tumor stroma in pancreatic cancer and their contribution to the failure of clinical trials: a systematic review and critical appraisal. Cancer Metastasis Rev 2015, 34:97-114.

142. Cukierman E: Stromagenesis. In Encyclopedia of Cancer, edn 2nd. Edited by Schwab M: Springer; 2009:2843-2845. vol 4.]

143. Stoker MG, Shearer M, O'Neill C: Growth inhibition of polyoma-transformed cells by contact with static normal fibroblasts. J Cell Sci 1966, 1:297-310.

144. Wadlow RC, Wittner BS, Finley SA, Bergquist H, Upadhyay R, Finn S, Loda M, Mahmood U, Ramaswamy S: Systems-level modeling of cancer-fibroblast interaction. PLoS One 2009, 4:e6888.

145. Vonlaufen A, Joshi S, Qu C, Phillips PA, Xu Z, Parker NR, Toi CS, Pirola RC, Wilson JS, Goldstein D, et al.: Pancreatic stellate cells: partners in crime with pancreatic cancer cells. Cancer Res 2008, 68:2085-2093.

146. Olive KP, Jacobetz MA, Davidson CJ, Gopinathan A, McIntyre D, Honess D, Madhu B, Goldgraben MA, Caldwell ME, Allard D, et al.: Inhibition of Hedgehog signaling enhances delivery of chemotherapy in a mouse model of pancreatic cancer. Science 2009, 324:1457-1461.

147. Thayer SP, di Magliano MP, Heiser PW, Nielsen CM, Roberts DJ, Lauwers GY, Qi YP, Gysin S, Fernandez-del Castillo C, Yajnik V, et al.: Hedgehog is an early and late mediator of pancreatic cancer tumorigenesis. Nature 2003, 425:851-856.

148. Bailey JM, Swanson BJ, Hamada T, Eggers JP, Singh PK, Caffery T, Ouellette MM, Hollingsworth MA: Sonic hedgehog promotes desmoplasia in pancreatic cancer. Clin Cancer Res 2008, 14:59956004.

149. Mills LD, Zhang Y, Marler RJ, Herreros-Villanueva M, Zhang L, Almada LL, Couch F, Wetmore C, Pasca di Magliano M, Fernandez-Zapico ME: Loss of the transcription factor GLI1 identifies a signaling network in the tumor microenvironment mediating KRAS oncogene-induced transformation. J Biol Chem 2013, 288:11786-11794.

150. Feldmann G, Habbe N, Dhara S, Bisht S, Alvarez H, Fendrich V, Beaty R, Mullendore M, Karikari C, Bardeesy $\mathrm{N}$, et al.: Hedgehog inhibition prolongs survival in a genetically engineered mouse model of pancreatic cancer. Gut 2008, 57:1420-1430.

151. Feldmann G, Fendrich V, McGovern K, Bedja D, Bisht S, Alvarez H, Koorstra JB, Habbe N, Karikari C, Mullendore $M$, et al.: An orally bioavailable small-molecule inhibitor of Hedgehog signaling inhibits tumor initiation and metastasis in pancreatic cancer. Mol Cancer Ther 2008, 7:27252735.

152. Feig C, Jones JO, Kraman M, Wells RJ, Deonarine A, Chan DS, Connell CM, Roberts EW, Zhao Q, Caballero OL, et al.: Targeting CXCL12 from FAP-expressing carcinoma-associated fibroblasts 
synergizes with anti-PD-L1 immunotherapy in pancreatic cancer. Proc Natl Acad Sci U S A 2013, 110:20212-20217.

** 153. Provenzano PP, Cuevas C, Chang AE, Goel VK, Von Hoff DD, Hingorani SR: Enzymatic targeting of the stroma ablates physical barriers to treatment of pancreatic ductal adenocarcinoma. Cancer Cell 2012, 21:418-429.

** This article demonstrates that reduction of discrete stromal components, such as HA, can effectively remodel stroma (i.e., alleviating blood vessel compression) thereby facilitating therapeutic delivery.

154. Toole BP: Hyaluronan: from extracellular glue to pericellular cue. Nat Rev Cancer 2004, 4:528-539.

155. Toole BP, Ghatak S, Misra S: Hyaluronan oligosaccharides as a potential anticancer therapeutic. Curr Pharm Biotechnol 2008, 9:249-252.

156. Tredan O, Galmarini CM, Patel K, Tannock IF: Drug resistance and the solid tumor microenvironment. J Natl Cancer Inst 2007, 99:1441-1454.

* 157. Evanko SP, Potter-Perigo S, Petty LJ, Workman GA, Wight TN: Hyaluronan controls the deposition of fibronectin and collagen and modulates TGF-beta1 induction of lung myofibroblasts. Matrix Biol 2015, 42:74-92.

* The focus of this article was to establish the role of the ECM associated glycosaminoglycan, Hyaluronan, in its interaction with fibronectin during TGF- $\beta$ driven fibroblastic activation. The paper highlights a mechanism by which ECM components influence myofibroblastic cytoskeletal organization (i.e., Cytoskeletal conduit).

158. Chauhan VP, Boucher Y, Ferrone CR, Roberge S, Martin JD, Stylianopoulos T, Bardeesy N, DePinho RA, Padera TP, Munn LL, et al.: Compression of pancreatic tumor blood vessels by hyaluronan is caused by solid stress and not interstitial fluid pressure. Cancer Cell 2014, 26:14-15.

** 159. Hingorani SR, Harris WP, Beck JT, Berdov BA, Wagner SA, Pshevlotsky EM, Tjulandin SA, Gladkov $\mathrm{OA}$, Holcombe RF, Korn R, et al.: Phase Ib Study of PEGylated Recombinant Human Hyaluronidase and Gemcitabine in Patients with Advanced Pancreatic Cancer. Clin Cancer Res 2016.

** This manuscript depicts a Phase-Ib clinical trial aimed at testing enzymatic degradation of stromal HA. The study served as basis for additional planned and ongoing stromal-reversion clinical trials that should benefit patients presenting high stromal HA expression.

* 160. Dekker TJ, Charehbili A, Smit VT, Ten Dijke P, Kranenbarg EM, van de Velde CJ, Nortier JW, Tollenaar RA, Mesker WE, Kroep JR: Disorganised stroma determined on pre-treatment breast cancer biopsies is associated with poor response to neoadjuvant chemotherapy: Results from the NEOZOTAC trial. Molecular Oncology 2015, 9:1120-1128.

* This article correlates tumoral matrix isotropic features with breast cancer patient responses to chemotherapy and its anisotropy with metastatic potentials.

161. Connolly EC, Freimuth J, Akhurst RJ: Complexities of TGF-beta targeted cancer therapy. Int J Biol Sci 2012, 8:964-978.

162. Neuzillet C, Tijeras-Raballand A, Cohen R, Cros J, Faivre S, Raymond E, de Gramont A: Targeting the TGF $\beta$ pathway for cancer therapy. Pharmacology \& Therapeutics 2015, 147:22-31.

163. Kelly M, Credill AJS: Nonclinical safety evaluation of a transforming growth factor $\beta$ receptor I kinase inhibitor in fischer 344 rats and beagle dogs. Journal of Clinical Toxicology 2014, 04.

164. Bogdahn U, Hau P, Stockhammer G, Venkataramana NK, Mahapatra AK, Suri A, Balasubramaniam A, Nair S, Oliushine V, Parfenov V, et al.: Targeted therapy for high-grade glioma with the TGFbeta2 inhibitor trabedersen: results of a randomized and controlled phase Ilb study. Neuro Oncol 2011, 13:132-142. 
165. Jaschinski F, Rothhammer T, Jachimczak P, Seitz C, Schneider A, Schlingensiepen KH: The antisense oligonucleotide trabedersen (AP 12009) for the targeted inhibition of TGF-beta2. Curr Pharm Biotechnol 2011, 12:2203-2213.

166. Schlingensiepen KH, Jaschinski F, Lang SA, Moser C, Geissler EK, Schlitt HJ, Kielmanowicz M, Schneider A: Transforming growth factor-beta 2 gene silencing with trabedersen (AP 12009) in pancreatic cancer. Cancer Sci 2011, 102:1193-1200.

167. Vallieres L: Trabedersen, a TGFbeta2-specific antisense oligonucleotide for the treatment of malignant gliomas and other tumors overexpressing TGFbeta2. IDrugs 2009, 12:445-453.

168. Brandes AA, Carpentier AF, Kesari S, Sepulveda-Sanchez JM, Wheeler HR, Chinot O, Cher L, Steinbach JP, Capper D, Specenier $\mathrm{P}$, et al.: A phase II randomized study of galunisertib monotherapy or galunisertib plus lomustine compared with lomustine monotherapy in patients with recurrent glioblastoma. Neuro Oncol 2016.

169. Fujiwara Y, Nokihara H, Yamada Y, Yamamoto N, Sunami K, Utsumi H, Asou H, Takahash IO, Ogasawara K, Gueorguieva I, et al.: Phase 1 study of galunisertib, a TGF-beta receptor I kinase inhibitor, in Japanese patients with advanced solid tumors. Cancer Chemother Pharmacol 2015, 76:1143-1152.

170. Rodon J, Carducci M, Sepulveda-Sanchez JM, Azaro A, Calvo E, Seoane J, Brana I, Sicart E, Gueorguieva I, Cleverly A, et al.: Pharmacokinetic, pharmacodynamic and biomarker evaluation of transforming growth factor-beta receptor I kinase inhibitor, galunisertib, in phase 1 study in patients with advanced cancer. Invest New Drugs 2015, 33:357-370.

171. Herbertz S, Sawyer JS, Stauber AJ, Gueorguieva I, Driscoll KE, Estrem ST, Cleverly AL, Desaiah D, Guba SC, Benhadji KA, et al.: Clinical development of galunisertib (LY2157299 monohydrate), a small molecule inhibitor of transforming growth factor-beta signaling pathway. Drug Des Devel Ther 2015, 9:4479-4499.

172. Serova M, Tijeras-Raballand A, Dos Santos C, Albuquerque M, Paradis V, Neuzillet C, Benhadji KA, Raymond $E$, Faivre $S$, de Gramont A: Effects of TGF-beta signalling inhibition with galunisertib (LY2157299) in hepatocellular carcinoma models and in ex vivo whole tumor tissue samples from patients. Oncotarget 2015, 6:21614-21627.

173. Ding N, Yu RT, Subramaniam N, Sherman MH, Wilson C, Rao R, Leblanc M, Coulter S, He M, Scott C, et al.: A vitamin D receptor/SMAD genomic circuit gates hepatic fibrotic response. Cell 2013, 153:601-613.

174. Bhattacharjee V, Zhou Y, Yen TJ: A synthetic lethal screen identifies the Vitamin D receptor as a novel gemcitabine sensitizer in pancreatic cancer cells. Cell Cycle 2014, 13:3839-3856.

175. Zhang Z, Yu X, Fang X, Liang A, Yu Z, Gu P, Zeng Y, He J, Zhu H, Li S, et al.: Preventive effects of vitamin D treatment on bleomycin-induced pulmonary fibrosis. Scientific Reports 2015, 5:17638.

** 176. Sherman MH, Yu RT, Engle DD, Ding N, Atkins AR, Tiriac H, Collisson EA, Connor F, Van Dyke T, Kozlov $S$, et al.: Vitamin $D$ receptor-mediated stromal reprogramming suppresses pancreatitis and enhances pancreatic cancer therapy. Cell 2014, 159:80-93.

** This article demonstrated the possibility to manipulate the stroma to reprise its tumor suppressive (i.e., original/innate) state. In doing so, the authors unveil a therapeutic option to transcriptionally reprogram the stroma environment, thereby aiding in chemotherapeutic responses.

177. Manson JE, Bassuk SS, Lee IM, Cook NR, Albert MA, Gordon D, Zaharris E, Macfadyen JG, Danielson E, Lin J, et al.: The VITamin D and OmegA-3 TriaL (VITAL): rationale and design of a large randomized controlled trial of vitamin $D$ and marine omega-3 fatty acid supplements for the primary prevention of cancer and cardiovascular disease. Contemp Clin Trials 2012, 33:159171. 
178. Chung M, Lee J, Terasawa T, Lau J, Trikalinos TA: Vitamin D with or without calcium supplementation for prevention of cancer and fractures: an updated meta-analysis for the U.S. Preventive Services Task Force. Ann Intern Med 2011, 155:827-838.

179. Boldogh I, Albrecht T, Porter DD: Persistent viral infections. In Medical Microbiology, edn 4th. Edited by Baron S; 1996.

180. Bjarnsholt T: The role of bacterial biofilms in chronic infections. APMIS Supp/ 2013:1-51.

181. He X, Tian Y, Guo L, Ano T, Lux R, Zusman DR, Shi W: In vitro communities derived from oral and gut microbial floras inhibit the growth of bacteria of foreign origins. Microb Ecol 2010, 60:665676.

182. Larsson PG, Forsum U: Bacterial vaginosis--a disturbed bacterial flora and treatment enigma. APMIS 2005, 113:305-316.

183. Francescone R, Hou V, Grivennikov SI: Microbiome, inflammation, and cancer. Cancer J 2014, 20:181-189.

184. Bjarnsholt T, Ciofu O, Molin S, Givskov M, Hoiby N: Applying insights from biofilm biology to drug development - can a new approach be developed? Nat Rev Drug Discov 2013, 12:791-808.

185. Bradshaw CS, Morton AN, Hocking J, Garland SM, Morris MB, Moss LM, Horvath LB, Kuzevska I, Fairley CK: High recurrence rates of bacterial vaginosis over the course of $\mathbf{1 2}$ months after oral metronidazole therapy and factors associated with recurrence. J Infect Dis 2006, 193:14781486.

Figure Legends:

Figure 1: Example of an epithelial cancer presenting high levels of desmoplastic stroma. Formalinfixed and paraffin-embedded surgical normal (non-pathological) and lung cancer (neoplastic) samples were subjected to indirect immunofluorescence. Cellular vimentin is shown in red and is intended to denote both normal and desmoplastic stromal cells. Pan-cytokeratin is in green highlighting epithelial as well as neoplastic cells. DNA intercalating agent, Hoechst, was used to stain nuclei of all cell types and is shown in blue. Note that the neoplastic tissue is enriched with (red) dense stromal cells in comparison to its non-pathological counterpart.

Figure 2: Stromal Dynamic Reciprocity amid fibroblastic cell-ECM interactions in innate vs.

desmoplastic homeostatic states. This model highlights the relationship between the cellular and ECM components of the mesenchymal-stroma demonstrating a dependence on this interplay to drive and maintain homeostatic states. The maintenance of the two homeostatic states is portrayed by the orbitlike arrows. The model depicts the phenotypical co-evolution of fibroblastic cells and their self-derived ECMs under the influences of a chronic assault (i.e. inflammation, cancer, etc.) suggesting possible restorative instances (i.e., therapies) of the innate, tumor-restrictive, stroma. Note that the cartoon includes a graphic representation of the cellular cytoskeleton which links, conveys and is modified in response to changes in both ECM and cellular states.

Figure 3: Stromal Dynamic Reciprocity model illustrating the likely peril of desmoplastic ablation. Innate SDR is the natural homeostatic stromal state in which tumor onset is repressed. When this environment is provisionally threatened (e.g., during infection or wounding), the innate homeostatic equilibrium transitions to a new, albeit short lived, homeostatic state: the acute SDR. In this homeostatic state, tissue repair is maintained until restoration is achieved. Following successful repair, and often after an acellular scar is formed, the system shifts or "tilts" back to the innate (tumor 
suppressive) homeostatic equilibrium. However, in the absence of wound resolution such as in the case of chronic inflammation and/or cancer, the acute SDR system is further sustained thus shifting the balance towards a third (chronic SDR) homeostatic equilibrium. During each of these transitions, extracellular and intracellular interactions are biophysically conveyed via the actomyosin cytoskeleton, which serves as a "conduit" transferring these mechanical cues amid cells and ECM. Note that this model suggests that a threat to the environment weakens the tumor restrictive (innate) capabilities in which, if not repaired (tilted back) in a timely fashion, cancer will be allowed to ensue (i.e., accompanied by a chronic/desmoplastic state). Additionally, this model proposes that ablation of chronic/desmoplastic SDR eliminates the possibility of shifting the system back to the innate tumor restrictive state. 


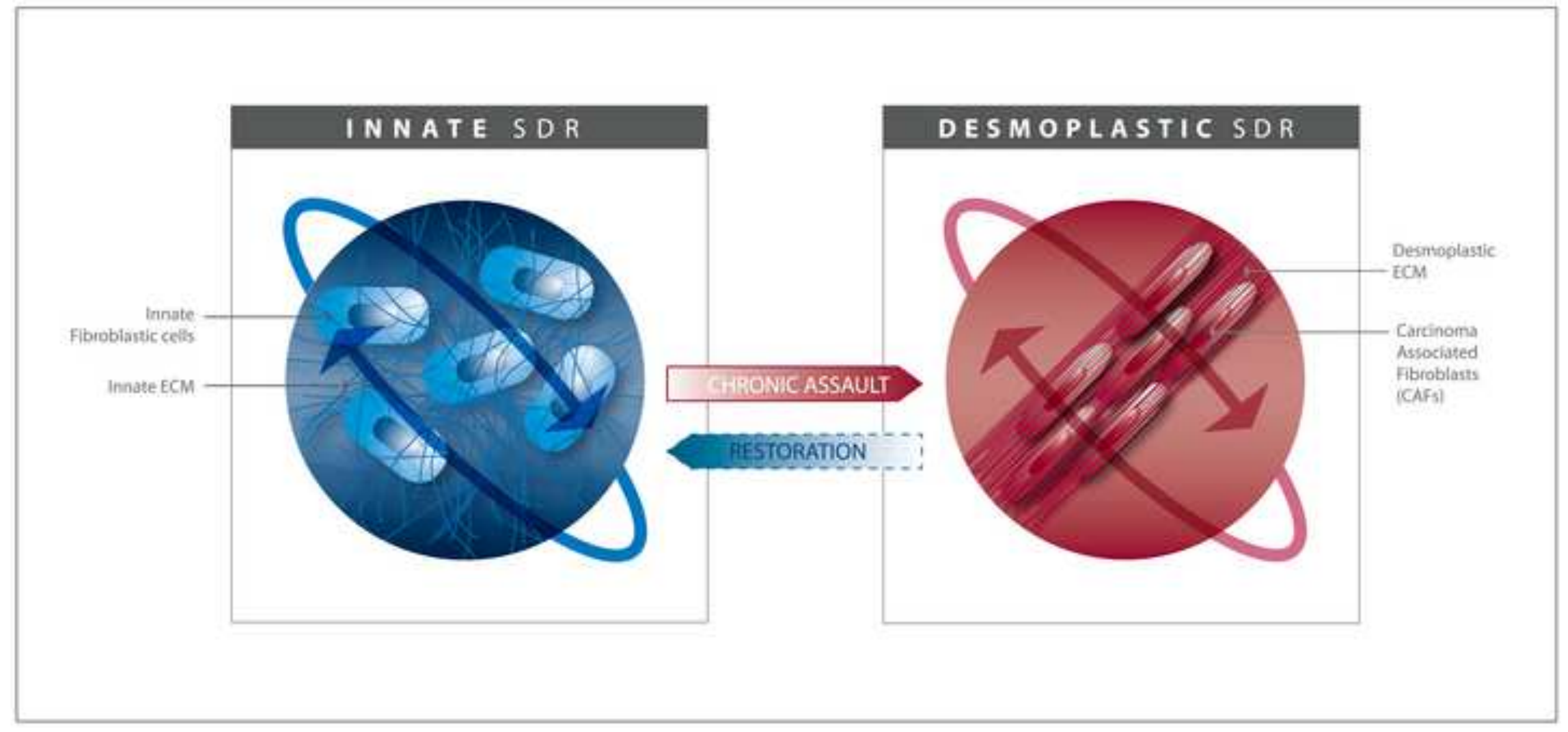




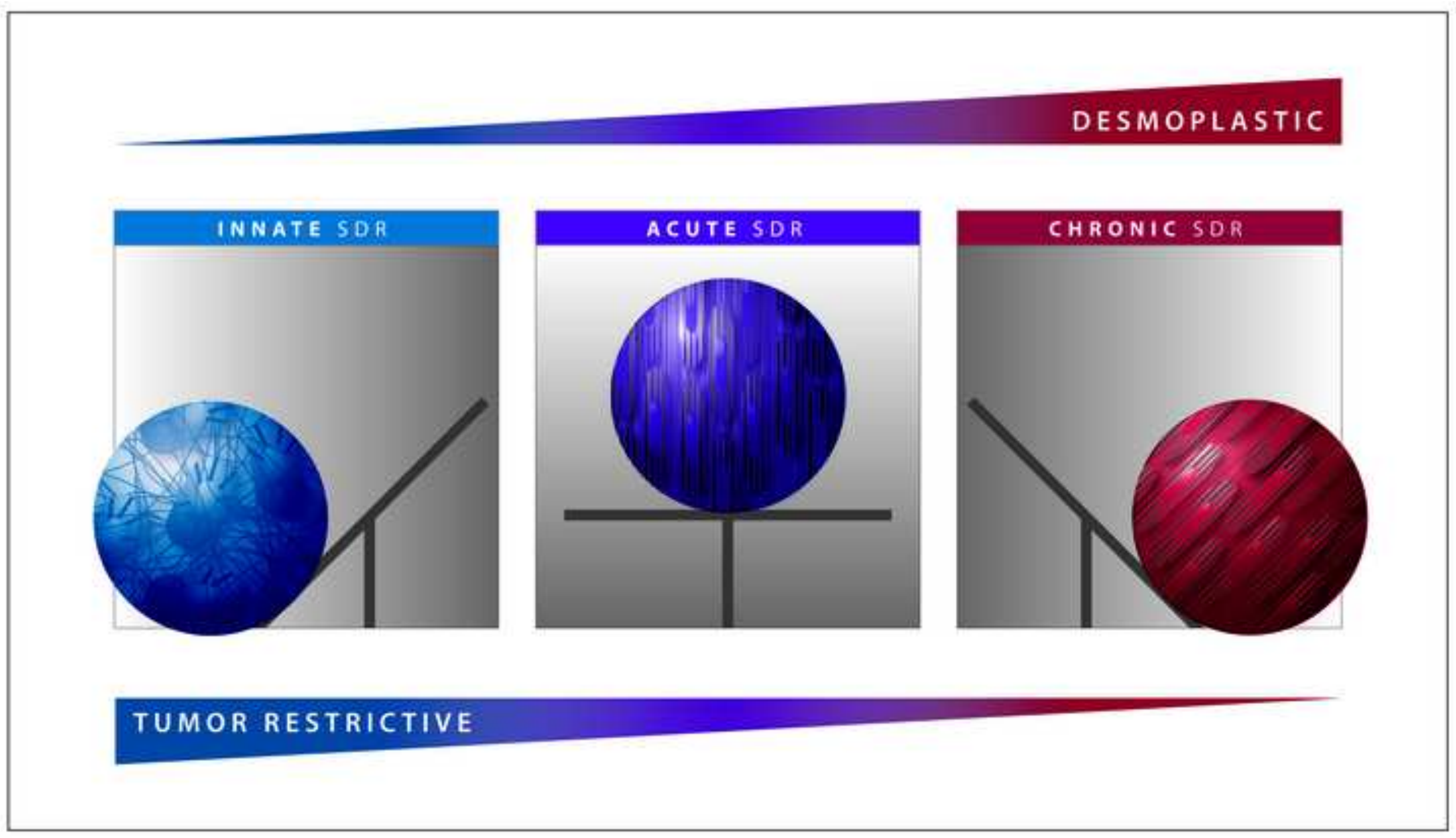


